\title{
Green Composites Using Lignocellulosic Waste and Cellulosic Fibers from Corn Husks
}

\author{
Terence P. Tumolva ${ }^{1, a}$, Danilo S. Enguero Jr. ${ }^{1}$, Tracy Joy C. Laus ${ }^{1}$, Benedict A. Requejo ${ }^{1}$ \\ ${ }^{1}$ University of the Philippines Diliman, Quezon City, Philippines
}

\begin{abstract}
This study explores the feasibility of using lignocellulosic waste and cellulosic fibers from corn husks in the production of green composites, with orthophthalic unsaturated polyester (ortho-UP) resin as a matrix. Lignocellulose was extracted from corn husk fibers by alkali treatment using $1 \mathrm{M} \mathrm{NaOH}$, and the dried lignocellulose extract was characterized using FTIR spectroscopy. Composites containing varying weight fractions of lignocellulose, treated fibers and ortho-UP were fabricated, and the tensile and flexural strengths and moduli were measured. Based on the results, it was observed that the composite containing $15 \mathrm{wt} \%$ fiber possesses the highest tensile modulus, while the one with $20 \mathrm{wt} \%$ lignocellulose showed the highest flexural modulus. The composites were also subjected to scanning electron microscopy to examine the fracture surfaces of the composites. Furthermore, the water sorption behavior of the composites was also studied, and it was observed that all the composites obey Fickian diffusion.
\end{abstract}

\section{Introduction}

Green composites that are partially or totally derived from biodegradable plant materials are viable alternatives to petroleum-based composites. Commercially used natural fibers are typically derived from agro-fiber plants such as abaca, kenaf and hemp; however, there is also an increasing trend in the use of agricultural residues such as sugarcane bagasse, rice hull and coconut coir as potential fiber sources.

Corn husk is a lignocellulosic material that currently has no established commercial value and is often simply considered as agricultural waste. In the Philippines, corn husk is very abundant and widely available since corn is the second most important crop of the country. To utilize this material as fiber reinforcement in the production of green composites, chemical treatments such as alkali must be employed to separate the cellulose from its other components such as lignin and hemicellulose, which are later disposed as lignocellulosic waste. Yin, et al. have reported that the corn-derived lignin in the waste may also be used to produce biocomposites [1]; however, purification of lignin can only be done with additional processing, which translates to additional energy and cost. In this study, it is proposed that the separated lignocellulosic wastes be blended raw into a polymer matrix as an extender rather than merely disposing them, and the resulting composite properties be evaluated.

\section{Experimental}

Corn husks were sourced from a local market in Quezon City, Philippines. For the lignocellulose extraction, 1M

\footnotetext{
${ }^{\mathrm{a}}$ Corresponding author: terence.tumolva@coe.upd.edu.ph
}

$\mathrm{NaOH}$ and $10 \mathrm{wt} \%$ aqueous $\mathrm{H}_{2} \mathrm{SO}_{4}$ were prepared. For the fabrication of the composites samples, orthophthalic polyester (ortho-UP) resin, R10-103 from Polymer Products (Phil) Inc., was used as polymer matrix with methylethyl ketone peroxide (MEKP) as hardener. A liquid release wax was also used to facilitate the easy removal of the composites from the curing molds.

\subsection{Alkali treatment}

The corn husks were first sun-dried for 12 hours and then crushed into short fibers using a mill. The fibers were then immersed in $1 \mathrm{M} \mathrm{NaOH}$, using a ratio of $1 \mathrm{~g}$ fiber to $15 \mathrm{~mL}$ of $\mathrm{NaOH}$ solution. The mixture was then heated at $170^{\circ} \mathrm{C}$ for 90 minutes (see Figure 1), and, afterwards, allowed to cool down for 30 minutes before filtering.

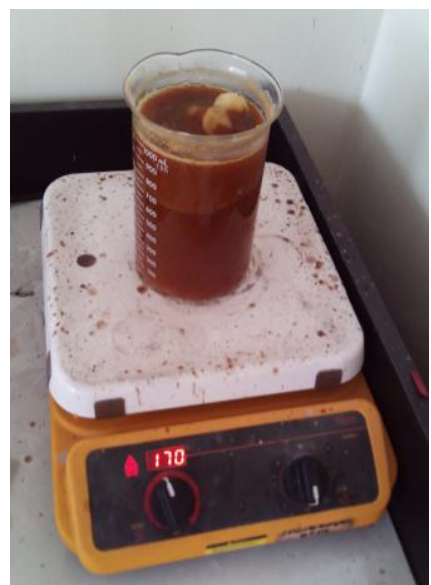

Figure 1. Alkali treatment set-up. 
The treated pulp was washed, dried, and set aside, while the filtrate was gradually acidified using $10 \mathrm{wt} \%$ $\mathrm{H}_{2} \mathrm{SO}_{4}$ to $\mathrm{pH}$ 5. The precipitation of lignocellulose would then begin as indicated by the change in the color of the liquid from dark brown to a lighter murky brown color. The solution was then heated in a water bath at $60^{\circ} \mathrm{C}$ for 30 minutes, and then further acidified down to $\mathrm{pH} 3$. The lignocellulose precipitates were allowed to settle for at least 1-2 hours and then separated by vacuum filtration for 6 to 8 hours; afterwards, the filter cake was sun-dried and pulverized.

\subsection{Composite fabrication}

Composite samples with varying ratios of lignocellulosic waste (LW), treated fiber and resin were prepared (see Table 1). Each component was weighed in an analytical balance and blended using a hand mixer. The resin mixture was then placed in a vacuum desiccator to remove air bubbles.

Table 1. Component weight fractions of fabricated composites.

\begin{tabular}{|l|c|c|c|c|}
\hline \multicolumn{1}{|c|}{ Sample } & $\begin{array}{c}\text { LW } \\
\text { wt\% }\end{array}$ & $\begin{array}{c}\text { Fiber } \\
\text { wt \% }\end{array}$ & $\begin{array}{c}\text { Resin } \\
\text { wt\% }\end{array}$ & $\begin{array}{c}\text { MEKP } \\
\text { wt\% }\end{array}$ \\
\hline Blank & 0 & 0 & 98.5 & 1.5 \\
\hline $\mathbf{1 0 \% ~ L W ~}$ & 10 & 0 & 88.5 & 1.5 \\
\hline $\mathbf{1 5} \%$ LW & 15 & 0 & 83.5 & 1.5 \\
\hline $\mathbf{2 0} \%$ LW & 20 & 0 & 78.5 & 1.5 \\
\hline $\mathbf{1 5} \%$ Fiber & 0 & 15 & 83.5 & 1.5 \\
\hline 1:1 (F:LW) & 10 & 10 & 78.5 & 1.5 \\
\hline 2:1 (F:LW) & 10 & 5 & 83.5 & 1.5 \\
\hline 1:2 (F:LW) & 5 & 10 & 83.5 & 1.5 \\
\hline
\end{tabular}

For the specimen preparation, the mixture was then poured into steel molds with dimensions that are in accordance to ASTM standards D638 and D790 for tensile and flexural tests, respectively, and placed in a thermal press set at $55^{\circ} \mathrm{C}$ for $4-5$ hours. The resulting specimens are shown in Figure 2 below.

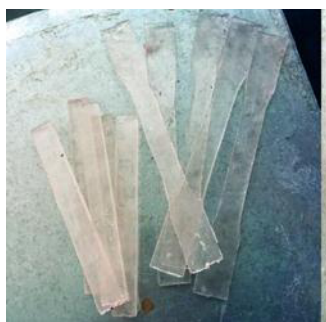

(a)

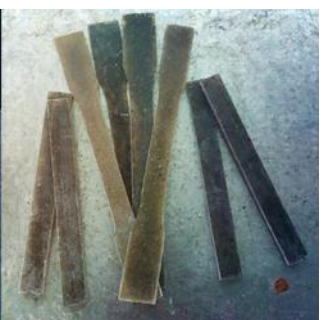

(b)
Figure 2. Fabricated specimens of (a) neat ortho-UP and (b) with corn husk fibers and lignocellulosic wastes.

\subsection{Tests and analyses}

The LW powder was subjected to Fourier transform infrared spectroscopy (FTIR) to verify the presence of lignin in the samples. Tensile and flexural tests were conducted using a universal testing machine to determine the mechanical properties of the samples. The fracture surfaces of the test specimens were then observed using a scanning electron microscope (SEM). Lastly, water sorption tests were done by immersing the samples in water at ambient temperature for 72 hours to study the water sorption behavior of the composites.

\section{Results and discussion}

\subsection{FTIR spectroscopy}

Figure 3 shows the FTIR spectrum generated by the dried pulverized lignocellulose extract from the corn husk. The spectrum was compared to the FTIR spectra of various lignin samples in the study reported by Lisperguer, et al. [2]. All spectra show a broad band between wavenumbers $3400-3500 \mathrm{~cm}^{-1}$ with similar peaks. These strong bands are attributed to the hydroxyl groups present in the phenolic and aliphatic structures of lignin. Hence, the presence of lignin in the samples could be confirmed based on the similarities in characteristic peaks.

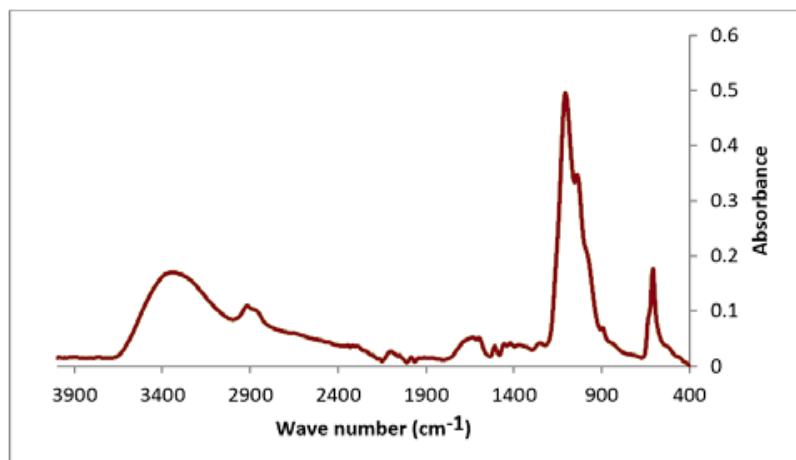

Figure 3. FTIR spectrum of dried lignocellulose powder.

\subsection{Tensile tests}

Figure 4 shows the tensile moduli of the corn husk composite samples. Among the samples made, it can be observed that the composite containing $15 \%$ fiber has the highest modulus, and the only one that is higher than that of a neat ortho-UP resin. It can also be observed that the composites containing both lignocellulosic waste and fibers have higher moduli than those of composites containing lignocellulosic waste only. This is because the rigid and somewhat brittle cellulosic fibers improve the composites' resistance to elongation during loading [3].

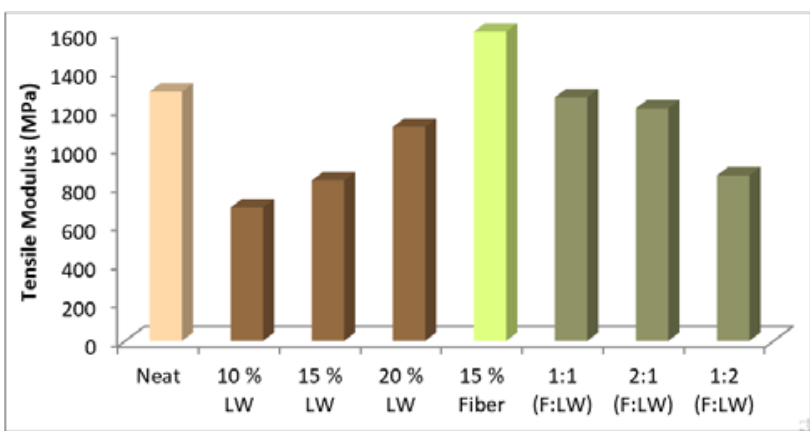

Figure 4. Tensile moduli of the corn husk green composites at varying fractions of fiber and lignocellulosic waste.

Figure 5 shows the tensile strengths of the different corn husk composites. It can be observed that the 
strengths of the corn husk fiber-reinforced composites are significantly lower than that of the neat resin, which is consistent with the results reported by Jaya Chitra and Vasanthakumari in 2012 [4]. This is an indication of the weak adhesion between the corn husk fibers and the ortho-UP matrix. Also, the results reveal that the simple mixing of the ortho-UP and LW produces a blend that is heterogeneous and has weaker tensile strength; this may be improved by initiating cross-linking between the lignin with the ortho-UP or by further polymerizing the lignin during the blending process.

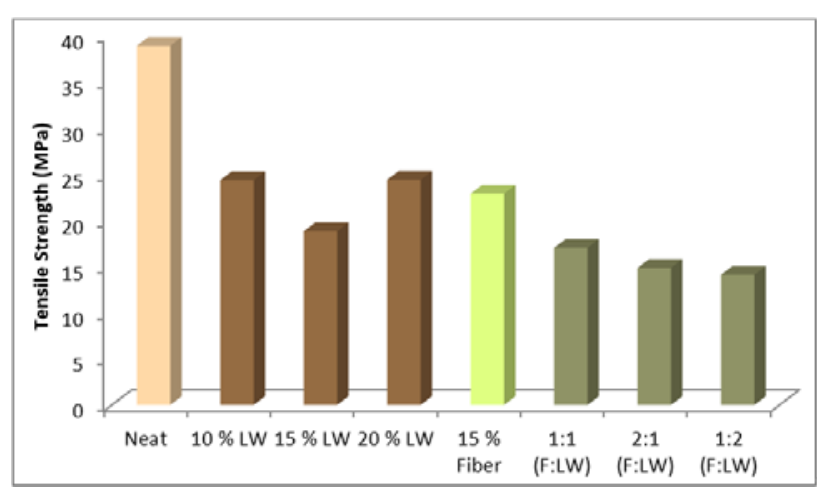

Figure 5. Tensile strengths of the corn husk green composites at varying fractions of fiber and lignocellulosic waste.

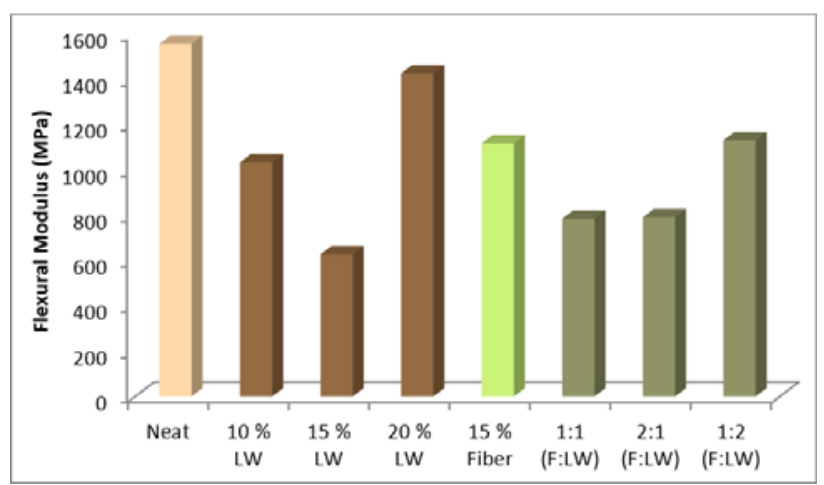

Figure 6. Flexural moduli of the corn husk green composites at varying fractions of fiber and lignocellulosic waste.

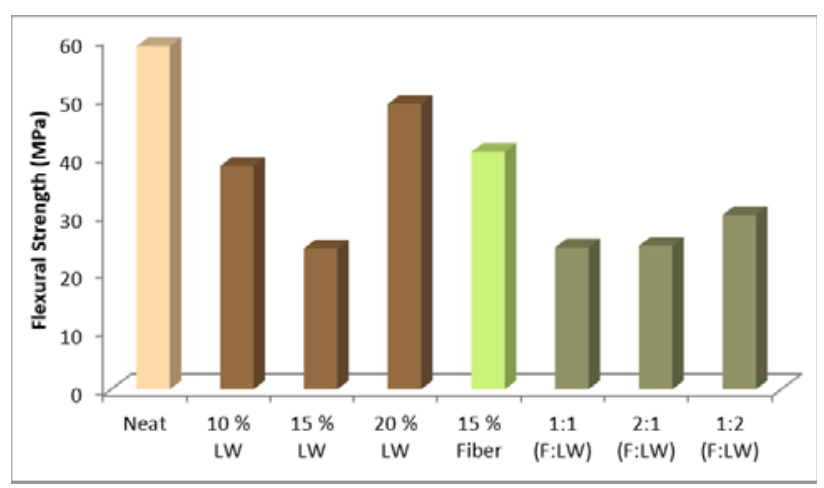

Figure 7. Flexural strengths of the corn husk green composites at varying fractions of fiber and lignocellulosic waste.

\subsection{Flexural tests}

Figures 6 and 7 show the flexural moduli and strengths of the corn husk green composites, respectively. The composite with $20 \%$ lignocellulose exhibits the highest modulus, comparable to that of the neat resin. From the results, it can be observed that the corn husk composites containing only the lignocellulosic waste have higher flexural strength and moduli than those containing corn husk fibers. As observed from the figures, there is always a sudden decrease in modulus and strength upon the introduction of a small amount of filler into the neat resin. This is because of the competing effects of introducing heterogeneity into the material and the plasticizing effect of the added lignocellulosic waste (due to the presence of hemicellulose). This means that increasing the amount of lignocellulosic waste can possibly overcome the negative effects of the introducing heterogeneity due to the increased presence of the fibers.

\subsection{Fracture surface morphology}

From the SEM images of the fracture surfaces for the different corn husk green composites, it can be observed that fracture surface becomes rougher as the amount of lignocellulose is increased, which can be attributed to the heterogeneous nature of the composite. From the comparison of Figures 8,9 and 10, it can be observed that the lignocellulosic particles become more apparently visible under SEM for the corn husk LW/ortho-UP blends with increasing lignocellulosic waste content.

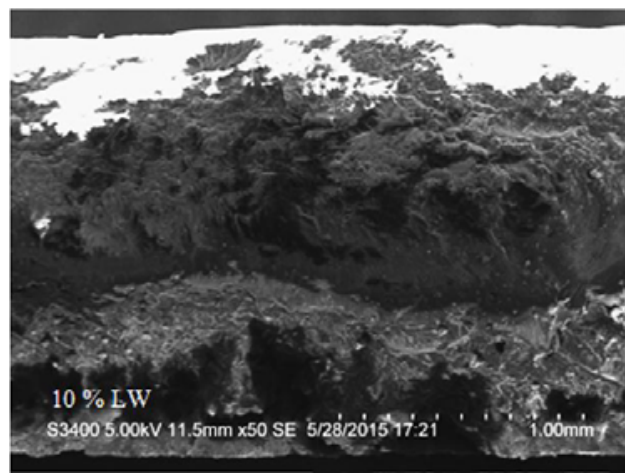

Figure 8. SEM image of the fracture surface for the $10 \%$ corn husk LW/ortho-UP blend.

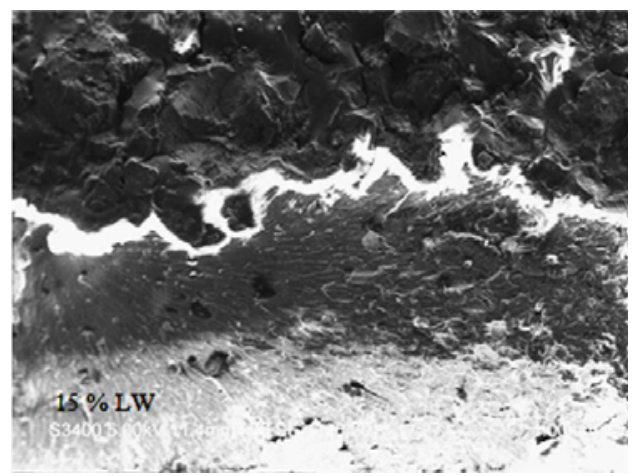

Figure 9. SEM image of the fracture surface for the $15 \%$ corn husk LW/ortho-UP blend. 


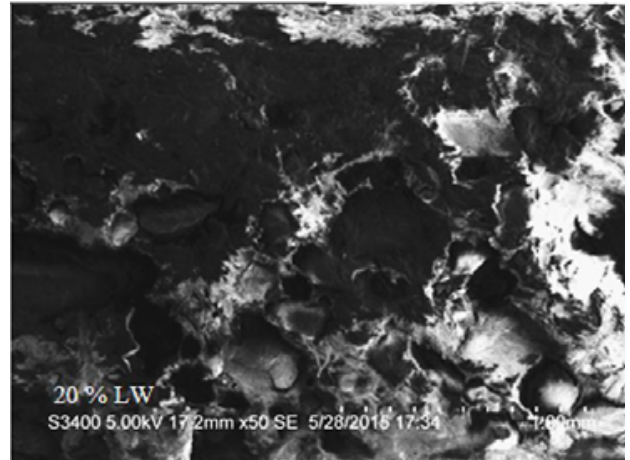

Figure 10. SEM image of the fracture surface for the $20 \%$ corn husk LW/ortho-UP blend.

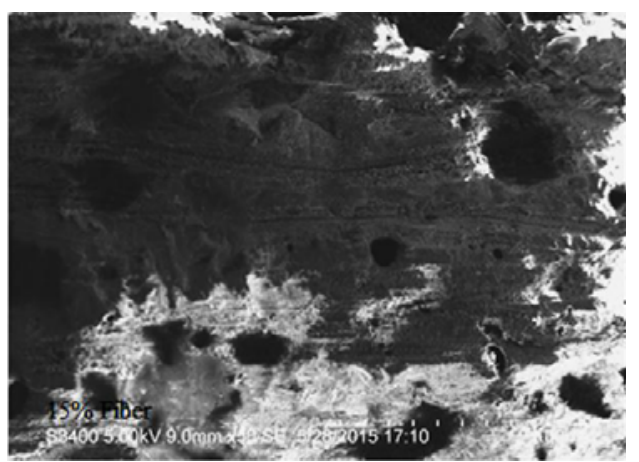

Figure 11. SEM image of the fracture surface for the $15 \%$ corn husk fiber green composite.

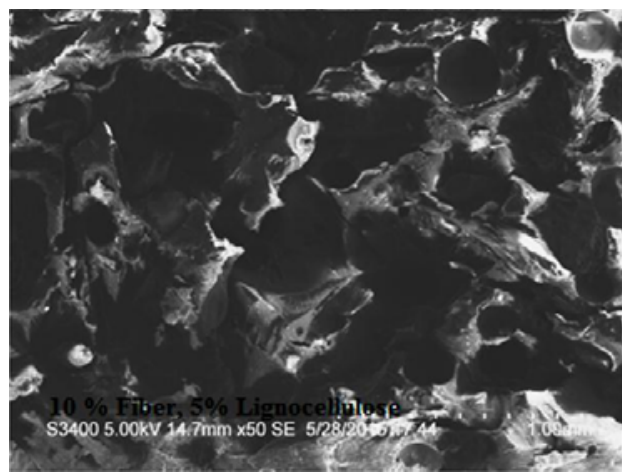

Figure 12. SEM image of the fracture surface for the $10 \%$ fiber $/ 5 \% \mathrm{LW}$ corn husk green composite.

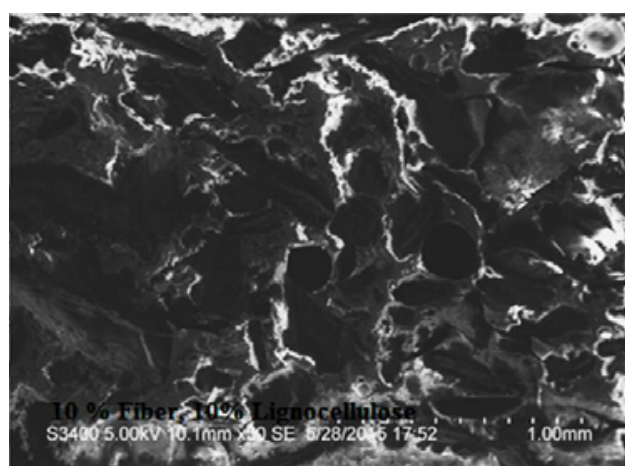

Figure 13. SEM image of the fracture surface for the $10 \%$ fiber $10 \%$ LW corn husk green composite.

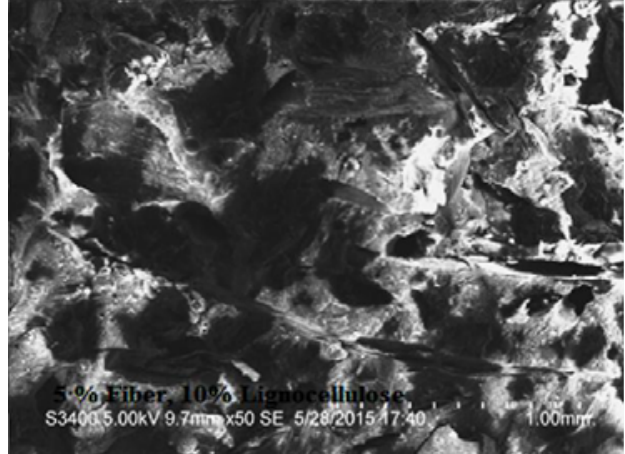

Figure 14. SEM image of the fracture surface for the 5\% fiber $/ 10 \%$ LW corn husk green composite.

The same trend is observed from the SEM images for the fracture surfaces of the corn husk fiber-reinforced composites, as shown in Figures 11 to 14. As the amount of lignocellulosic waste is increased, the fracture surface becomes rougher. The presence of voids that can be observed from the SEM images of these fiber-containing composites are due to fiber pull-out during testing.

\subsection{Water sorption}

Water retention is observed for the prepared green composites that has been immersed in water at ambient temperature for 72 hours, with the total mass of the wet specimens measured at different points in time using an analytical balance. Figure 15 shows the change in the weight of the composites over time. It can be observed that the addition of the hydrophilic cellulose fibers and the heterogeneity brought by the introduction of the lignocellulosic waste have increased the hydrophilicity of the polymer composite. Additionally, the presence of the corn husk fibers also increases the water sorption of the composite because of the lumen they inherently possess [5]. This may be remedied by improving the blending procedure and by using a more effective fiber treatment.

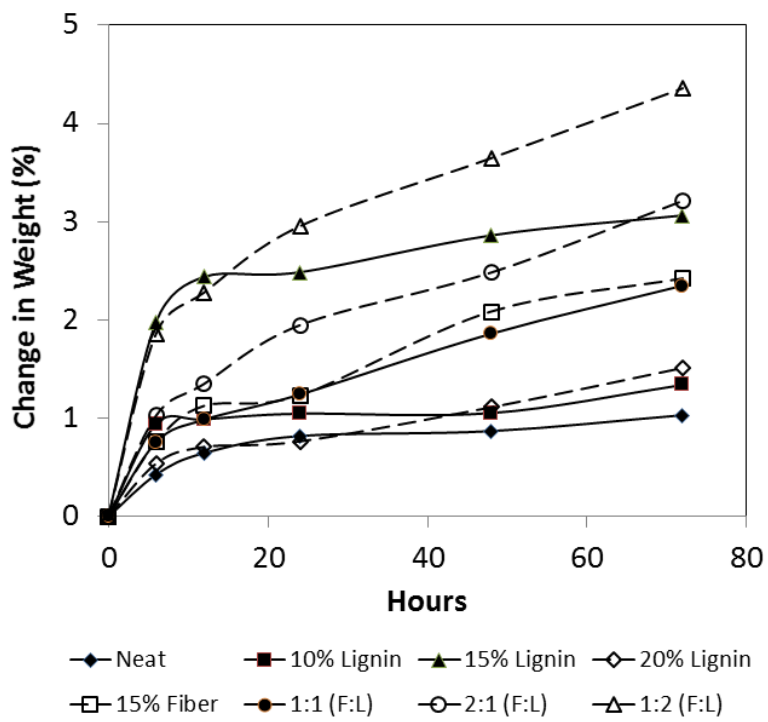

Figure 15. Percent weight change with time due to water sorption of the different corn husk green composites. 
Figure 16 shows the plot of the change in weight plotted against the square root of time. A linear trend can be observed for all the samples since the equilibrium moisture contents of the composites are not yet reached after 72 hours; however, the results are still consistent with the expected Fickian diffusion behavior of the water sorption of green composites [6].

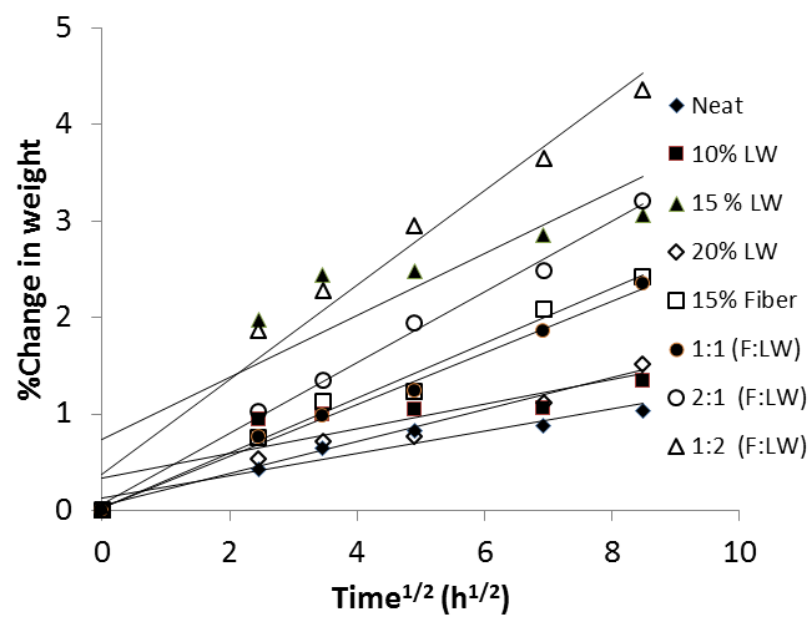

Figure 16. Percent weight change due to water sorption of the different corn husk green composites against $\mathrm{t}^{1 / 2}$.

Figure 17 shows the total change in weight of the samples after 72 hours. The change in weight ranges from $1.03 \%$ to $4.36 \%$. As expected, the corn husk fiber-filled composites absorbed the most amount of water due to the lumen and the hydrophilic nature of cellulose. The fibermatrix interface also contributes to the hydrophilicity [7]. On the other hand, the lignocellulosic waste/ortho-UP blends generally have a lower weight change because the lignin is less hydrophilic than cellulose, especially after it has been subjected to alkali treatment (which reduces the number of active hydroxyl groups).

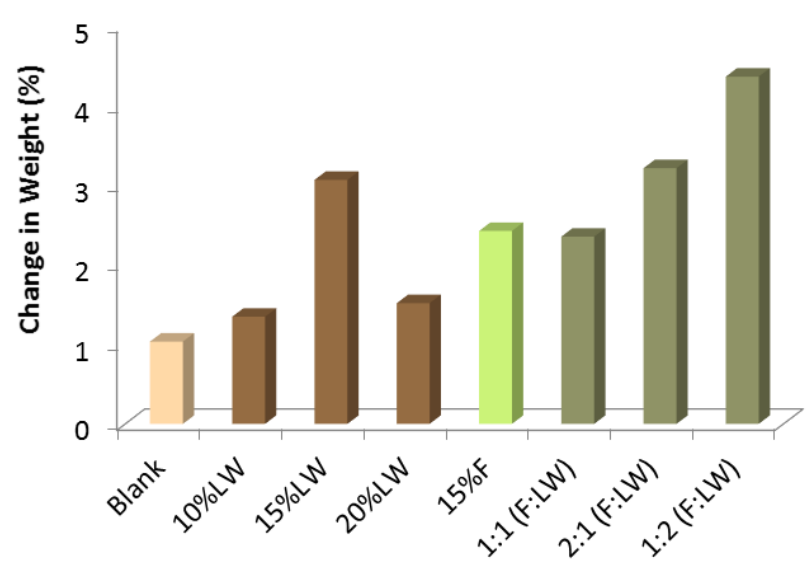

Figure 17. Total weight change due to water sorption of the different corn husk green composites after 72 hours.

The increased water sorption can also be caused by the presence of voids in the composites resulting from the failure of fiber-matrix adhesion. This is because alkali treatment only increases surface roughness to improve mechanical interlocking and does not chemically alter the fibers [8]. Lastly, neat ortho-UP resin exhibits the lowest weight change from the water immersion due to its inherent hydrophobicity.

\section{Conclusions and Recommendations}

Green composites using corn husk fibers and lignocellulosic waste and unsaturated polyester resin can be produced. Composites with $15 \%$ fibers exhibited the highest tensile properties. Also, the addition of fibers improves the tensile properties of the composite. Among the prepared green composites, the one with $20 \%$ lignocellulosic waste shows the highest flexural strength and modulus. Among the corn husk composites containing both fibers and lignocellulosic waste, the one with 1:1 ratio of $\mathrm{LW} /$ fiber has the highest tensile properties, while the one with a 1:2 LW/fiber ratio has the highest flexural strength and modulus. Overall, the addition of the recycled corn husk fillers shows a slight decrease in strength but a retention of moduli compared to that of a neat ortho-UP resin.

The corn husk composites obey Fickian diffusion, and the addition of fillers causes an increase in the amount of water that can be absorbed. Lignin-containing composites generally exhibited lower water sorption than fibercontaining composites.

For future studies, it is recommended to use a wider range of lignocellulosic waste weight fractions and more variations in the fiber-to-lignocellulose ratio. Also, other properties of the composites such as wet mechanical properties and thermal properties must still be evaluated. This study may also be extended to the use of other polymeric resins. Lastly, optimization studies may be conducted and the interaction of various parameters still needs to be explored.

\section{References}

1. Q. Yin, W. Yang, C. Sun, M. Di, BioResources 7, 4 (2012)

2. J. Lisperguer, P. Perez, S. Urizar, J. Chil. Chem. Soc. 54, 4 (2009)

3. D. Ray, B.K. Sarkar, A.K. Rana, N.R. Bose, Bull. Mater. Sci. 24, 2 (2001)

4. N. Jaya Chitra, R. Vasanthakumari, Int. J. Sci. Eng. Res. 3, 7 (2012)

5. T. Tumolva, M. Kubouchi, S. Aoki, T. Sakai, Proceedings of JCOM-38, 310-313 (2009)

6. M. Kubouchi, T. Tumolva, Y. Shimamura, BiofiberReinforced Thermoset Composites, in Polymer Composites 3, 213-237 (2013)

7. T. Tumolva, M. Kubouchi, S. Aoki, T. Sakai, Materials Science and Technology of Japan 48, 8794 (2011)

8. R. Lopez, V.M. Poblano, A. Licea-Claverie, M. Avalos, A. Alvarez-Castillo, V.M. Castaño, Adv. Composite Mater. 9, 2 (2000) 